\title{
Древние города России, их статус и проблемы сохранения архитектурного наследия
}

\author{
М.В.Нащокина, НИИТИАГ, Москва
}

Древние города - это важнейшие свидетельства истории и территориальной целостности России, значимые для её самоидентификации. Статья посвящена проблемам определения, статуса древних городов нашей страны и сохранения их архитектурного наследия. Автор ставит вопрос о том, что называть древними городами, все ли они сейчас защищены законом как исторические города? Большинство исследователей считают таковыми домонгольские города, основанные примерно, начиная с IX века до 1230 годов, то есть до начала монгольских вторжений. Среди них сегодня есть малонаселённые и утратившие городской статус посёлки, состоящие из архитектурных или археологических памятников - Изборск, Старая Рязань, Старый Льгов, Ростиславль-Рязанский, Пронск, Херсонес, Булгар и т.д., и города развивающиеся, среди которых явно выделяются крупные города - Ярославль, Рязань, Брянск, Великий Новгород и Псков, большинство же - города малые.

В современных условиях России для многих из них самой важной задачей является сохранение населения, дающего надежду на будущее развитие. Нужно очень многое сделать для коренной переоценки исконных национальных ценностей - мировоззрения, образа жизни и быта, чтобы привычная штурмовщина и революционные ломки сменились на бережные и здравые эволюционные подходы. В статье рассматриваются вопросы функциональной ориентации городов и занятий их жителей в историческом аспекте. Выдвигаются конкретные предложения о возможной функциональной переориентации городов, о путях решения современных социальных и градостроительных проблем, которые позволят занять жителей исторических городов, а следовательно, не потерять возможность сохранения их архитектурного наследия. Необходимо осознать, что сбережение древних и более молодых исторических городов России - общенародная задача, важное основание самоуважения нации и едва ли не самое наглядное свидетельство её права на занимаемую территорию.

Ключевые слова: древние города России, домонгольские города, своеобразие русских провинциальных городов, проблема занятости населения, традиционный русский дом.

Ancient Cities of Russia, Their Status and Problems of Preservation of Architectural Heritage

M.B.Nashokina, NIITIAG, Moscow

The article is devoted to the problems of determining the status of the ancient cities of Russia and the preservation of their architectural heritage. The author raises the question of what to call ancient cities, whether all of them are now protected by law as historical cities, etc. Most researchers believe those are the pre-Mongol towns, founded from the IX century till 1230, before the start of the Mongol invasions. Among them today there are sparsely populated settlements (some of them lost township status) consisting of architectural or archaeological monuments - Izborsk, Old Ryazan, Old Lgov, Rostislavl-Ryazansky, Pronsk, Chersonesus, Bulgar, etc., and developinglarge citieslike Yaroslavl, Ryazan, Bryansk, Novgorod, and Pskov, but most of them are small towns.

The question of the functional orientation of cities and occupations of their inhabitants in the historical aspect is considered. The author suggests ways of solving modern social and urban problems that will occupy the population of historical cities, and therefore not to lose the ability to preserve their architectural heritage.

Keywords: ancient cities of Russia, pre-Mongol cities, originality of Russian provincial cities, the problem of employment, traditional Russian house.

Летом 2018 года в Рязани состоялся Первый международный форум древних городов России, что заставило поразмышлять на затронутые в его программе темы. Представляется, что заявленное в названии форума словосочетание «древние города» нуждается в уточнении - что называть древними городами в России? Совпадают ли древние города с историческими городами России? Имеют ли они особый статус?

Большинство российских исследователей считают таковыми домонгольские города, основанные примерно, начиная с IX века до 1230 годов, то есть до начала монгольских вторжений. Примерно половина их, входивших в Киевское, Переяславское, Полоцкое и Черниговское княжества, сегодня находятся вне территории России ${ }^{1}$. Остались города Новгородской и Псковской республик, Белозёрского, Владимиро-Суздальского, Муромо-Рязанского и Смоленского княжеств. Из них старше всех, видимо, Великий Новгород (859) и следом ещё шесть городов, отсчитывающих свой возраст с 862 года - Изборск, Ростов, Муром, Ладога, Белоозеро и Смоленск; далее в хронологическом порядке: Псков (903), Углич (937), Трубчевск (975), Брянск (985), Владимир (990), Суздаль (999), Ярославль (1010), Переяславль Рязанский (Рязань) (1095), Старая Рязань (1096), Мстиславль (1135), 
Пронск (1131), Рославль (1137), Козельск (1146), Каргополь (1146), наконец, Москва (1147), Дорогобуж (1150), Звенигород (1152), Переславль-Залесский (1152), Рыльск (1152), Юрьев Польской (1152), Ростиславль-Рязанский (1153), Гороховец (1162), Льгов (1207) и т.д. Это города Древней Руси.

Немало древних городов есть и на территории современной России - прежде всего, это города Крымского полуострова - Керчь (VII в. до н.э.), Херсонес (528 г. до н.э.), Феодосия (355 г. до н.э.), Судак (212), а также Дербент (VI в. до н.э.), Булгар (Х в.), Казань (1005) и многие другие, в том числе археологические города-памятники, расположенные в разных частях страны².

Названные города сильно различаются по численности населения (мегаполис Москву мы не рассматриваем). Среди них есть малонаселённые и утратившие городской статус посёлки, состоящие сегодня в основном из архитектурных или археологических памятников - Изборск, Старая Рязань, Старый Льгов, Ростиславль-Рязанский, Пронск, Херсонес, Булгар и т.д., и города развивающиеся, среди которых явно выделяются крупные города - Ярославль, Рязань, Брянск, Великий Новгород и Псков, большинство же - города малые. Подчеркнуть это важно - если крупные города более самостоятельны в финансовом отношении, наименее защищены именно малые города ${ }^{3}$.

Древние города - это важнейшие свидетельства истории и территориальной целостности нашей страны, значимые для её самоидентификации. Облик многих из них до сих пор сохраняет неповторимую атмосферу, единение с природным ландшафтом, своеобразие и красоту в её ощутимом национальном понимании. Русский архитектор начала XX века Гавриил Барановский считал, что «красота города является высшей формой искусства - всеобъемлющей, так как в ней отражается бытовая и умственная культура народа, и в то же время - истинно национальной, так как влияние её на массы неотразимо». Думается, что сохранение национального своеобразия городов является сегодня насущной задачей для России, которая ещё не отошла от политики безоглядного заимствования западных подходов и ценностей во всех сферах жизни. В этом аспекте не лишнее посмотреть на архитектурную практику стран Востока, которые считают интеграцию западных ценностей в архитектуру угрозой национальной культуре и вновь обращают внимание на традиционное видение природы и открытых пространств ${ }^{4}$.

На первый взгляд все древние города России априори должны обладать статусом исторического города, однако это не так. В куцый федеральный список исторических городов 2010 года, которые всё же получают государственную финансовую помощь для своего благоустройства и реставрации наследия, вошли из приведённого перечня всего 10 городов ${ }^{5}$, к тому же древние археологические города (ныне посёлки) в этот список, как правило, вообще не входят. Конечно, это издержки сегодняшнего дня, но реальность именно такова и, безусловно, нуждается в корректировке.

Традиционно считается, что наиболее острой проблемой исторических городов России, в том числе древних, является сохранение их исторического наследия. Это действительно сложная и многоаспектная задача. В древних городах это требует не только выделения и благоустройства археологических памятников - рвов, валов, раскопов, реставрации архитектурных объектов культурного наследия, но и поддержания гораздо более молодой традиционной застройки, в основном малоэтажной. Эту задачу часто сводят исключительно к проблемам финансирования и ужесточения режимов застройки, хотя опыт показывает, что эти рычаги часто неэффективны в той мере, в какой в данном случае требуется.

Как представляется, в современных условиях России гораздо более важной задачей для многих из перечисленных древних городов является сохранение их населения, которое позволяет надеяться на будущее развитие. Конечно, это государственная задача, впрямую зависящая от экономической и социальной политики и находящаяся вне сферы архитектурной компетенции, но чтобы принимаемые меры были действенными, необходимо пересмотреть подходы к ним.

В докладе об архитектурном наследии Венеции в Москве профессор Р. Чевезе высказал странную для нашего понимания в 1982 году мысль: «Проблема сохранения Венеции - это проблема сохранения венецианцев». Глубочайший смысл её для нас в те годы ещё не был очевиден - казалось, что спасти Венецию могут только дорогостоящие инженерные мероприятия, комплексные реставрационные работы и т.д. Но ведь Венеция - это не только дома и храмы, но, прежде всего, её жители, создавшие в течение столетий уникальную атмосферу города и особый образ жизни. Отток венецианцев, продающих свои дома богатым иностранцам, изредка их посещающим, неизбежно выхолащивает живой дух Венеции, превращают её в город безудержного потребления, один из многих туристских центров мира. Не будем вдаваться в подробности, какие меры принимает Италия для противо-

\footnotetext{
${ }^{1}$ Киев (VI в.), Чернигов (907), Переяславль (Хмельницкий) (907), Витебск (947), Полоцк (862), Перемышль (981), Житомир (884), Любеч (882), Пересечен (922), Вышгород (946), Искоростень (946).

2 Часть перечисленных городов вошла в куцый список исторических городов России 2010 года - Белозёрск, Владимир, Дербент, Ростов, Смоленск, Суздаль и Ярославль.

${ }^{3}$ В России около 750 малых городов с населением до 50 тыс. жителей. Это три четверти всех городов страны [1, с. 226].

4 Доклад Дианы Мензис (Новая Зеландия) - экс-президента IFLA и президента Новозеландского института ландшафтных архитекторов на Международном Конгрессе Всемирной Федерации ландшафтных архитекторов (IFLA) в С.-Петербурге, 10-12 июня 2015 г.

${ }_{5}^{5}$ Это - Юрьев-Польской, Козельск, Звенигород, Трубчевск, Гороховец, Дорогобуж, Суздаль, Каргополь, Белозёрск и Болгар.
} 
стояния этому процессу, но вывод, к которому давно пришли итальянские учёные, носит, безусловно, всеобщий характер - сохранение физических параметров архитектурного наследия без заинтересованного в этом населения и, хотя бы частичного, сохранения соответствующего ему образа жизни попросту невозможно. Только стремление самих жителей продлить жизнь родных городов и существование своих старинных домов может уберечь их от безвозвратной утраты - именно это сохранило до наших дней исторические города Италии.

Безответственная политика почти сто лет истребляла у русского человека привязанность к родной земле, к месту жительства и занятиям предков. На протяжении прошедшего столетия считалось необходимым отбросить все устаревшее: представления, ценности, культуру, города, дома - всё. И эта установка по инерции продолжает действовать сегодня.

Быстро исчезает традиционная городская деревянная застройка. Традиционный русский дом, без сожаления, вычеркнут из национальной системы ценностей, а потому практически не востребован и стремительно уходит в прошлое. А ведь в каждом из регионов нашей страны деревянный крестьянский дом имел свои образные, художественные и строительные особенности, испокон веков обеспечивая и развивая богатство традиционной народной культуры. Это хорошо известно историкам, этнографам, культурологам. Однако вряд ли можно утверждать, что это общеизвестно.

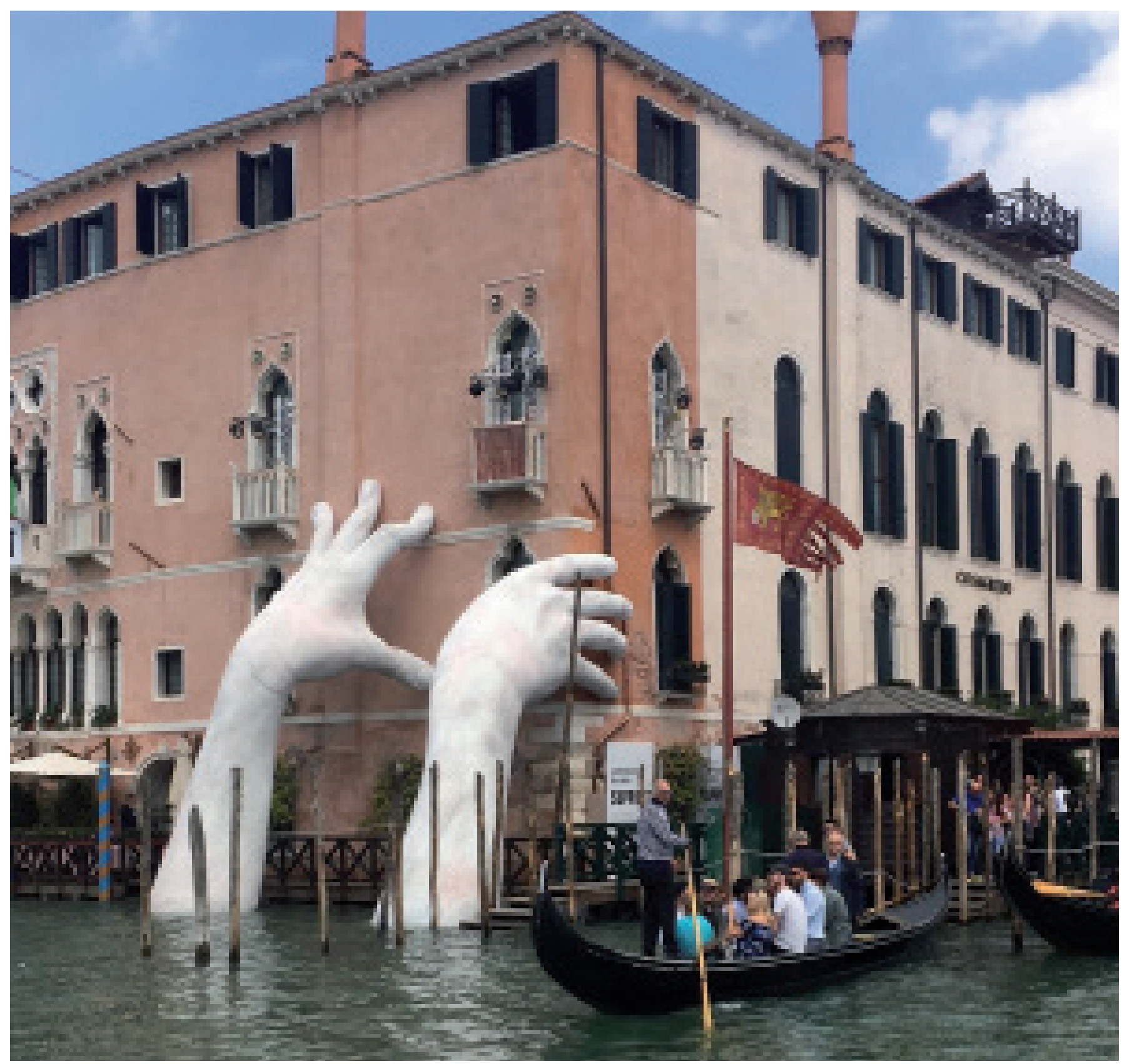

Источник: Константин Дорошенко. Венецианская биеннале: за все хорошее, против всего плохого // «Зеркало недели. Украина». URL: https://zn.ua/ CULTURE/venecianskaya-biennale-za-vse-horoshee-protiv-vsego-plohogo-248833_html 
Совершенно очевидно, что вследствие последовательной вековой пропаганды ценностей городской жизни и урбанизации, традиционный русский деревянный дом почти совсем потерял привлекательность в качестве основного жилья. Большинством горожан и сельских жителей России он не воспринимается ни как национальное культурное достояние, ни как эстетическая ценность ${ }^{6}$.

Уже около века в нашей прессе социальный прогресс выражается в замене индивидуальных деревянных жилищ типовыми панельными многоквартирными домами. И это в стране с беспрецедентным по масштабу экспортом древесины. Предпочтение многоквартирного городского дома базируется на вполне объективных причинах - любая квартира, пусть даже в неказистой пятиэтажке, оснащена инженерными сетями, которые делают ее априори комфортнее. Однако, что мешает их сейчас провести в сохранившиеся во многих городах исторические деревянные дома, особенно в городах богатых, крупных, в областных центрах? Ведь тогда владельцы старинных деревянных домиков сразу превратятся в хозяев городских особняков с приусадебными садами, что сделает их жизнь однозначно комфортнее и, по сути, явится реальным возрождением традиционного образа жизни русского города $и$ свидетельством заботы о благе народа. Это, кстати, уже стали кое-где понимать сами жители, не желая расставаться с родовыми гнёздами ${ }^{7}$. Однако сразу обозначились и противостоящие этому силы в строительной сфере, получающие сегодня сверхприбыли от интенсивного многоэтажного строительства $и$, естественно, не заинтересованные в сохранении исторической деревянной застройки, которая обычно занимает центральные, а значит самые престижные и дорогие городские территории.

Нужно очень многое сделать для коренной общественной переоценки исконных национальных ценностей - мировоззрения, образа жизни и быта, чтобы привычная штурмовщина и революционные ломки сменились на бережные и здравые эволюционные подходы. Для замедления центростремительной тенденции в движении населения, к сожалению, подкреплённой сегодня всеми СМИ, важно сделать жизнь в небольших исторических городах притягательной, акцентировать те её достоинства, которых нет в крупном городе. К счастью, во многих малых городах России ещё сохраняют свою значимость родственные и родовые связи ${ }^{8}$, живёт приверженность более спокойному и размеренному укладу жизни, что необходимо поддерживать всеми социокультурными мерами. Определённым цементирующим потенциалом обладает и возрождающаяся приходская жизнь.

Что же такое небольшой исторический русский город с точки зрения функции? Это одно или несколько мелких производств (в том числе сельскохозяйственных) - пекарни, молочные заводики и т.д., приусадебные участки с огородами и близость природы. Из прессы известно, что в России в последние годы перестали работать 78000 предприятий ${ }^{9}$, не только градообразующих, но и жизнеобеспечивающих, - и это впрямую коснулось исторических городов. Следствие отток трудоспособного населения и старение остающегося, которое уже не в состоянии поддерживать ветшающие дома. Результат - в перспективе скорое исчезновение многих исторических городов, в том числе древних.

8 декабря 2011 года министр экономического развития Э. Набиуллина на Международном урбанистическом форуме в Москве сообщила, что количество малых и средних городов в России в течение ближайших лет будет сокращаться, её министерство готовит к выводу из числа городов 208 субъектов РФ. Это примерно 40\% от числа малых городов и около $20 \%$ от общего числа городов. Российская экономика сегодня опирается только на крупные города, обладающие человеческими ресурсами и потенциалом роста, поддержание стабильности существования малых и средних городских образований в неё не вписывается. Как известно, современная бюджетно-налоговая политика не позволяет городу обращать на себя даже заработанное - в городском бюджете остаётся всего 1,5\% собранных средств. Спасительным кругом для обнищавших исторических городов в последние годы считается туризм, однако для большинства малых городов - экономический эффект от него минимален, львиную долю прибылей получают туроператоры. Таким образом, без кардинального решения проблемы занятости населения сохранить большинство небольших исторических городов с их наследием невозможно.

${ }^{6} 06$ этом можно судить не только по опросам населения, которое до сих пор, в основном, мечтает переехать в многоквартирные новостройки, но и по дачной застройке последнего времени, в которой явно преобладают капитальные строения. Если в московских или петербургских пригородах строятся деревянные постройки, то состоятельная публика предпочитает отнюдь не русский дом, а финские сборные и немецкие фахверковые дома или швейцарские шале. И, кстати, понятно почему: и в Скандинавии (в Финляндии, Норвегии, Дании), и в Швейцарии, и в Германии, и во Франции, да и по всей Европе бытует подлинный культ своего национального дома, который бережно и любовно до мелочей обихожен и приспособлен к современным требованиям комфорта.

7 Пример: борьба московских властей с владельцами деревянных домов в Бутове, на окраине города; жители Ефремова, переоборудующие деревянные дома под постоянное жилье и т.д.

${ }^{8}$ Щенков А.С. (руководитель). Историко-культурные проблемы реконструкции застройки малых городов России. Отчёт по научной теме НИИтИАГ. М., 2016. (рукопись); [2].

${ }^{9}$ К примеру, за последние годы обанкрочены и свёрнуты даже такие уникальные производства, как заводы художественного стекла («Красный май», бывший завод Болотиных в Ключах, Тверская область), хрусталя (завод в Дятькове Брянской области), Чудовский стекольно-хрустальный завод (Новгородская область), музыкальных инструментов (гитарный завод в Звенигороде), каждый из которых мог бы стать профилирующим для этих городов. В 2010-е годы закрыты и расхищены Гусевский завод в Гусе-Хрустальном (Владимирская область; закрыт в 2012 году), Бахметьевский завод в Никольском (Пензенская область, реконструирован и обновлён итальянским оборудованием в 2012 году, обанкрочен в 2014 году) и другие. Уничтожение стекольно-хрустальной отрасли - заводов, основанных ещё в XVIII веке и изготовлявших не только художественные изделия, но и органическое стекло для военной промышленности, заставляет предполагать лоббирование интересов иностранных компаний аналогичного профиля. 
Только целенаправленная забота о сохранении населения и образе его жизни в исторических городах России может принести ощутимые плоды. Для этого требуется продуманная градостроительная политика, учитывающая особенности каждого города и использующая разнообразие функциональных решений. Среди них одно из первых мест занимает возрождение местной промышленности, обновление которой требует значительных средств и должно быть увязано со специализацией, ресурсами и потребностями региона. Важнейшей отраслью может и должна стать строительная - организация артелей, направленных на поддержание и возобновление жилого фонда. Для сохранения единства архитектурной среды исторических городов не лишними могут оказаться многовариантные образцовые проекты, ведь большинство домов в них - не столько уникальны, сколько ценны своим стилевым подобием. Почему не использовать проверенный временем собственный исторический опыт в сфере жилого строительства, имевший в XIX-XX веках несомненный успех? Такое решение может принести положительные плоды именно в исторических городах, где проблема сохранения общего характера исторической застройки стоит особенно остро.

Перспективными направлениями развития средних и малых исторических городов могут стать также организованный отдых, кустарные производства, ремесла и промыслы, размещение крупных образовательных учреждений (университетов и академий с кампусами) и, наконец, сельское хозяйство: весьма востребованные сегодня экологически чистые овощеводство и животноводство. Напомним, что своеобразием отличались не только архитектурно-планировочные и функциональные особенности малых городов России, но и состав их жителей. Как известно, ведущим сословием Российской империи - огромной аграрной державы - было крестьянство, жившее не только в сёлах и деревнях, но и в городах. Почти

\footnotetext{
${ }^{10}$ Например, в Валуйках в середине XIX века из 5 тыс. жителей 3 тысячи были крестьянами. Исследователь городского хозяйства в конце XIX века писал: «Уездные города: Звенигород, Руза, Волоколамск теперь, как и прежде, сохраняют характер земледельческий. Нынешний город Ярославской губернии Ростов населён огородниками, Таруса (Калужской губ.) хлебопашцами, Боровск (тоже Калужской губ.) занимается разведением чеснока и луку и т.д.» $[3$, с. 9].
}

до конца XIX века сельское хозяйство наряду с ремёслами и торговлей оставалось основным занятием большинства провинциальных городов России, включая Москву. Горожане владели земельными угодьями за городскими границами и обрабатывали их ${ }^{10}$. Да, и сегодня, для малых городов это вполне возможно. Если сразу за городской чертой Амстердама ходят тучные стада, что, кроме бесхозяйственности и коррумпированной продажи земли под тотальную застройку, мешает им ходить вокруг городов Центральной России?

Конечно, могут быть востребованы и другие подходы и решения, главное нужно помнить, что сбережение древних и более молодых исторических городов России - важная общенародная задача, важное основание самоуважения нации и едва ли не самое наглядное свидетельство ее права на занимаемую территорию.

\section{Лumepamypa}

1. Резер Т.М., Сарычев А.М. Особенности развития малого города в Свердловской области / Т.М. Резер, А.М. Сарычев // Вопросы государственного и муниципального управления. 2013. - № 1. - С. 225-233.

2. Илюхина А.Ю. Социальный капитал малого российского города на примере г. Городец и г. Гусев / А.Ю. Илюхина // Малые города, большие проблемы. Социальная антропология малого города. - М., 2014. - С. 73-86

3. Щепкин М.П. Опыты изучения общественного хозяйства и управления городов. Ч.1. / М.П. Щепкин. - М., 1882.

\section{References}

1. Rezer T.M., Sarychev A.M. Osobennosti razvitija malogo goroda $v$ Sverdlovskoj oblasti [Features of the development of a small city in the Sverdlovsk region]. Voprosy gosudarstvennogo i municipal'nogo upravlenija [State and Municipal Administration Issues], 2013, no. 1. pp. 225-233.

2. Iljuhina A.Ju. Social'nyj kapital malogo rossijskogo goroda na primere g. Gorodec i g. Gusev [Social capital of a small Russian city on the example of Gorodets and Gusev]. Malye goroda, bol'shie problemy. Social'naja antropologija malogo goroda [Small cities, big problems. Social anthropology of a small city]. Moscow, 2014, pp. 73-86.

3. SHHepkin M.P. Opyty izuchenija obshhestvennogo hozjajstva i upravlenija gorodov Ch.1 [Experiments in the study of social economy and management of cities] P. 1. Moscow, 1882.

Нащокина Мария Владимировна (Москва). Доктор искусствоведения, академик РААСН. Главный научный сотрудник, заведующая отделом филиала ФГБУ «ЦНИИП Минстроя России» Научно-исследовательского института теории и истории архитектуры и градостроительства (111024, Москва, ул. Душинская, 9. НИИТИАГ). Эл. почта: n_maria53@mail.ru.

Naschokina Maria Vladimirovna (Moscow). Doctor of Art, Academician of RAACS. Chief Researcher, Head of the Branch Office of the Research Institute of Theory and History of Architecture and Urban Planning (9 Dushinskaya st., Moscow, 111024. NIITIAG), branch of the Central Institute for Research and Design of the Ministry of Construction and Housing and Communal Services of the Russian Federation (TsNIIP).Al. Email:n_maria53@mail.ru. 